\title{
United we stand, divided we fall: a meta-analysis of experiments on clonal integration and its relationship to invasiveness
}

\author{
Yao-Bin Song • Fei-Hai Yu • Lidewij H. Keser • \\ Wayne Dawson · Markus Fischer • Ming Dong • \\ Mark van Kleunen
}

\begin{abstract}
Many ecosystems are dominated by clonal plants. Among the most distinctive characteristics of clonal plants is their potential for clonal integration (i.e. the translocation of resources between interconnected ramets), suggesting that integration may play a role in their success. However, a general synthesis of effects of clonal integration on plant performance is lacking. We conducted a meta-analysis on the effects of clonal integration on biomass production and asexual reproduction of the whole clone, the recipient part (i.e. the part of a clone that imports resources) and the donor part (i.e. the part of a clone that
\end{abstract}

Communicated by Laura Gough.

Electronic supplementary material The online version of this article (doi:10.1007/s00442-012-2430-9) contains supplementary material, which is available to authorized users.

Y.-B. Song · M. Dong ( $\bowtie)$

College of Life and Environmental Sciences, Hangzhou Normal University, Hangzhou 310036, Zhejiang, China

e-mail: dongmingchina@126.com

\section{Y.-B. Song · F.-H. Yu - M. Dong}

State Key Laboratory of Vegetation and Environmental Change, Institute of Botany, Chinese Academy of Sciences, 100083 Beijing, China

F.-H. Yu (ه)

College of Nature Conservation, Beijing Forestry University, 100093 Beijing, China

e-mail: feihaiyu@bjfu.edu.cn

\section{H. Keser - M. Fischer}

Institute of Plant Sciences, University of Bern,

Altenbergrain 21, 3013 Bern, Switzerland

L. H. Keser - W. Dawson - M. van Kleunen

Department of Biology, University of Konstanz,

Universitätsstrasse 10, 78457 Konstanz, Germany exports resources). The final dataset contained 389 effect sizes from 84 studies covering 57 taxa. Overall, clonal integration increased performance of recipient parts without decreasing that of donor parts, and thus increased performance of whole clones. Among the studies and taxa considered, the benefits of clonal integration did not differ between two types of experimental approaches, between stoloniferous and rhizomatous growth forms, between directions of resource translocation (from younger to older ramet or vice versa), or among types of translocated resources (water, nutrients and carbohydrates). Clonal taxa with larger benefits of integration on whole-clone performance were not more invasive globally, but taxa in which recipient parts in unfavorable patches benefited more from integration were. Our results demonstrate general performance benefits of clonal integration, at least in the short term, and suggest that clonal integration contributes to the success of clonal plants.

Keywords Clonal plants - Environmental heterogeneity · Global compendium of weeds - Invasiveness .

Physiological integration

\section{Introduction}

Plants with asexual reproduction (i.e. clonal plants) occur in many different taxonomic groups (Klimeš et al. 1997), and are dominant in many natural and man-made ecosystems (Prach and Pyšek 1994; Klimeš et al. 1997). Moreover, among invasive species in many alien floras, clonal plant species such as Alternanthera philoxeroides (Mart.) Griseb., Eichhornia crassipes (Mart.) Solms, Spartina anglica C.E. Hubbard, and Solidago canadensis L. are among the most invasive (Pyšek 1997; Lowe et al. 2000; Liu et al. 
2006). Therefore, an important question in ecology and evolution is what makes clonal plants so successful.

The success of clonal plants may be due to distinctive clonal life-history traits (Tamm et al. 2002; van Kleunen et al. 2002). One of these traits is clonal integration, i.e. the ability to share resources such as water, carbohydrates and mineral nutrients between interconnected clone parts (ramets or groups of ramets; de Kroon et al. 1996; Hutchings and Wijesinghe 1997; Herben and Suzuki 2002). Clonal integration may be advantageous because it allows older ramets to support developing younger ramets, and because it allows support of clone parts growing in low-resource patches (Alpert 1999; Herben 2004; Wang et al. 2009). Clonal integration should particularly benefit the recipient ramets of the clone, and this could be at a cost to the donor ramets (de Kroon et al. 1996; Wang et al. 2009). If the benefits to the recipient ramets exceed the costs to the donor ramets, clonal integration will increase the fitness of the whole clone (i.e. the genetic individual; van Kleunen et al. 2000), which may give an advantage to clonal species over non-clonal species. However, it is not clear whether there are any patterns in the strength of the effects of integration among clonal plant species. Moreover, it is not known whether effects of clonal integration are related to the success of the clonal plant species.

Studies on the effects of clonal integration have used two major approaches (de Kroon et al. 1996; Jónsdóttir and Watson 1997). Some studies looked at the effects of severing the physical connection between different parts of a clone (e.g., Alpert 1999; van Kleunen et al. 2000; Yu et al. 2008). This severing approach might overestimate the effects of clonal integration, because severing might cause physiological stress and may make the plants more vulnerable to pathogen infections (Jónsdóttir and Watson 1997). Therefore, other studies left the connections intact but exposed the connected clone parts either to homogeneous or to heterogeneous conditions (Stuefer et al. 1994; He et al. 2011). This homogeneous-heterogeneous approach, however, may underestimate the effects of clonal integration, because the implicit assumption that there is no resource translocation under homogeneous conditions might not hold (e.g., Wang et al. 2009). So far, it has not been tested whether measured effects of clonal integration depend on the experimental approach.

Effects of clonal integration may differ between species with different clonal forms, i.e. between stoloniferous and rhizomatous species. Previous studies found that stolons (i.e. aboveground creeping stems) and rhizomes (i.e. belowground creeping stems) have partly different functions (Dong and de Kroon 1994). For instance, rhizomes can store a larger amount of reserves such as carbohydrates and proteins, and usually persist longer in the field than stolons (Dong et al. 1996; Suzuki and Stuefer 1999). Moreover, rhizomes can take up nutrients directly from the soil and transport them to the ramets (Brooker et al. 1999). Furthermore, some studies found that rhizomes are less plastic than stolons in response to changes in resource availability (Dong and de Kroon 1994; de Kroon and Hutchings 1995), and-if this is a general pattern-rhizomatous species may be more reliant on clonal integration as a means of coping with environmental heterogeneity than stoloniferous species. For these reasons, one might expect that rhizomatous species have a higher capacity for clonal integration than stoloniferous species.

Effects of clonal integration may also depend on the potential direction of resource translocation, i.e. whether it is from developmentally older to developmentally younger ramets (acropetal) or from developmentally younger to developmentally older ramets (basipetal) (Marshall et al. 1990; Jónsdóttir and Watson 1997). Studies using labeled resources have shown that acropetal translocation is usually more common than basipetal translocation within a plant (Marshall et al. 1990; de Kroon et al. 1996; D’Hertefeldt and Jónsdóttir 1999). The latter most likely reflects that clonal integration in many plants primarily provides support to establishing daughter ramets. However, this does not necessarily mean that effects of clonal integration on plant performance will be larger when resources are translocated acropetally (Stuefer et al. 1994). Moreover, the effect of integration could depend on the resource (i.e. water, nutrients or carbohydrates) that is being translocated (van Kleunen and Stuefer 1999). So far, it has not been tested whether the effects of integration depend on the kind of resources and the direction of resource translocation.

The success of clonal plants is not only apparent from their high frequencies in native floras but also in the fact that many invasive alien plants, particularly in (semi-)natural areas, are clonal, and that many of the most invasive plants are clonal (Pyšek 1997; Lowe et al. 2000; Liu et al. 2006). This suggests that clonal life-history traits may play a key role in plant invasiveness ( $\mathrm{Yu}$ et al. 2009; Aguilera et al. 2010; Xu et al. 2010). Although this hypothesis has been posed repeatedly, there have so far been no explicit tests. If clonal integration is usually advantageous and results in larger size and more offspring, one might expect that species with higher levels of integration are more successful than species with lower levels of integration, and thus are also more likely to have become invasive.

We conducted a meta-analysis of existing experimental studies on the effects of clonal integration to address the following specific questions. (1) Are the effects of clonal integration generally positive? (2) Are effects of integration estimated in experiments using a severing treatment larger than when estimated using comparisons between plants growing in heterogeneous and homogeneous environments? (3) Are effects of integration larger for rhizomatous plants than for stoloniferous plants? (4) Are the 
effects of integration larger for acropetal translocation than for basipetal translocation? (5) Do effects of integration depend on the kind of resource being translocated? And (6) are species with larger benefits of integration more invasive at a global scale? In this meta-analysis, we only considered the short-term benefits and costs associated with clonal integration. We could not address the long-term benefits and costs-for example, due to possible trade-offs between sharing resources among ramets and storage (e.g., Poor et al. 2005) - because most experimental studies of clonal integration lasted only a few months.

\section{Materials and methods}

\section{Selection of studies on clonal integration}

To collect studies that quantified the effects of clonal integration, we searched ISI Web of Science (http://apps. isiknowledge.com) on 20 April 2011, using the keyword combinations 'clon* integration' and 'physiolog* integration'. We also added studies listed in the references of the articles we obtained, including unpublished data in theses and non-English articles that did not appear in ISI Web of Science. In total, we found 158 studies covering 98 taxa.

We used the following criteria to select among these 158 studies the experimental ones that were suitable for metaanalysis. (1) We only included studies that reported means, sample sizes and standard errors or standard deviations for treatment and control, because these data are required to calculate effect sizes of clonal integration and their variances; and (2) we only included studies that reported effects of integration on biomass production and/or asexual reproduction (i.e. number of ramets). These are common measures of fitness in clonal plants (Pan and Price 2001). We did not include data on effects of integration on sexual reproduction because these studies were too scarce. The final dataset contained 389 cases from 84 studies covering 57 taxa (see Electronic supplementary material, ESM S1).

\section{Data extraction and calculation of effect sizes}

We extracted data on biomass and asexual reproduction for the whole clone, the potential recipient part, and/or the potential donor part. Where possible, we distinguished between whether the potential recipient and donor parts were the developmentally older or younger parts of the clone. When extracting biomass data, our first choice was to use data on total biomass. If instead of total biomass the biomasses of different plant parts (e.g., root mass and mass of leaves) were reported, we extracted these data, and later pooled the effect sizes of each of these parts per species and study (see below).
We extracted means, sample sizes and standard deviations or standard errors for biomass and asexual reproduction of the whole clone, and the potential recipient and donor parts. We extracted the data directly from tables and the main text or from graphs using the program ImageTool (http://ddsdx.uthscsa.edu/dig/itdesc.html). Where necessary, we obtained data directly from the corresponding authors of the papers. We also extracted from each paper data on the duration of the experiment (ESM S1).

Effect sizes are based on the difference between a 'treatment' and a 'control'. To get positive signs of effect sizes for benefits of integration, we considered treatments in which resource translocation was possible or most likely as 'treatment', and treatments in which resource translocation was prevented or unlikely as 'control'. This means that, for studies that used the severing approach, the treatment with intact connections (i.e. with resource translocation possible) was used as 'treatment' and the treatment with severed connections (i.e. with resource translocation not possible) as 'control'. For studies that left all connections intact but used the heterogeneous versus homogeneous approach, we considered the heterogeneous treatment (i.e. resource translocation is likely) as 'treatment' and the homogeneous treatment (i.e. resource translocation is not likely) as "control'. The latter approach could only be used to look at effects of integration for potential recipient clone parts (i.e. clone parts exposed to relatively low local resource availability) and donor clone parts (i.e. clone parts exposed to relatively high local resource availability). Here, we only compared clone parts of the same developmental stage and with the same local conditions, where one part was connected to another clone part experiencing the same conditions (i.e. homogeneous treatment) and the other one to a clone part experiencing different conditions (i.e. heterogeneous treatment).

We used pairs of 'treatment' and 'control' as defined above to calculate effect sizes (Hedges' $d$ ) and their variances following Rosenberg et al. (2000). These calculations were performed with the software MetaWin, v.2.1 (Rosenberg et al. 2000). When a study included separate data for more than one genotype or environment, we first calculated effect sizes and their variances for each pair separately. To avoid pseudo-replication, we pooled effect sizes and their variances of different genotypes or environments per species and study by doing a separate metaanalysis on these effect sizes (sensu Leimu et al. 2006), and used the pooled effect sizes in the final analyses.

Global invasion success of study species

As studies usually did not refer to the invasion success of their study species, we used the Global Compendium of Weeds (GCW; Randall 2002) to get estimates of global 
invasiveness for our species. The GCW is a list of plant species (over 28,000 taxa) that have been cited in primary literature, floras, and government reports (a total of 300 references) as weeds in a given location (Randall 2002). The number of these references in the GCW that list a species as being a weed has been used as a continuous index of global invasiveness in recent studies (Pyšek et al. 2009; Schlaepfer et al. 2010; Dawson et al. 2011; Jenkins and Keller 2011). Although the accuracy of the GCW has been criticized (Richardson and Rejmánek 2004), it is the best available and most comprehensive database on global invasiveness of plants (Pyšek et al. 2009). Because some global regions may have a greater bias in recording alien invasive species, the number of references in the GCW may not clearly indicate the global level of species invasiveness (Dawson et al. 2011). Therefore, we also used another proxy of invasiveness proposed by Dawson et al. (2011), which is the number of global regions containing a GCW reference. We $\log +1$-transformed numbers of GCW references and numbers of GCW regions prior to analysis.

\section{Data analysis}

All analyses were conducted with the software MetaWin, v.2.1 (Rosenberg et al. 2000). In the final analyses, we deleted one outlier with an extremely high effect size. However, before doing so, we confirmed that the results were qualitatively the same when including this outlier in the analyses. We used the random-effects model setting, which assumes that the differences among studies are not only due to sampling error but also due to true random variation, as is the default for ecological data (Gurevitch and Hedges 2001).

For each mean effect size, we calculated the bias-corrected $95 \%$ bootstrap confidence intervals based on 4,999 permutations (Adams et al. 1997). Using this method, a mean effect size is significantly different from zero when its $95 \%$ confidence interval does not include zero. For the recipient and the donor parts, we compared mean effect sizes between different categories (i.e. experimental approaches, clonal forms, directions of resource translocation and kinds of resources being translocated). We first used Chi-squared tests to assess whether heterogeneity among effect sizes $\left(Q_{\text {total }}\right)$ was significantly larger than the expected sampling error. Then, we calculated heterogeneity in effect size between categories $\left(Q_{\mathrm{b}}\right)$ and within groups $\left(Q_{\mathrm{w}}\right)$, and tested their significances with a randomization test and a Chi-squared test, respectively (Rosenberg et al. 2000). A significant $Q_{\mathrm{b}}$ suggests that the categorical variable explained a significant part of the heterogeneity, while a significant $Q_{\mathrm{w}}$ implies that there was still heterogeneity in effect sizes among studies not explained by the categorical variable (Rosenberg et al. 2000).
For the whole clones, we could only use data based on the severing approach. The resulting dataset allowed us to compare mean effect sizes between different clonal forms, but not between directions of resource translocation or kinds of resources being translocated. To assess whether effect sizes of clonal integration were associated with global invasiveness, we tested whether the slope of a regression with global invasiveness as an explanatory variable was significantly different from zero with a randomization test (Rosenberg et al. 2000).

To examine whether there was evidence for a publication bias (i.e. whether significant findings have a greater chance to be published than non-significant ones), we inspected funnel and normal-quantile plots, performed Spearman's rank-order correlation tests, and estimated failsafe numbers (Palmer 1999; Jennions and Møller 2002), as implemented in MetaWin. The scatter plot of effect size versus sample size showed a funnel-shaped distribution without any obvious underrepresentation of effect sizes (ESM S2A, S3A). The normal quantile plot showed that effect sizes were normally distributed (ESM S2B; Rosenberg et al. 2000). Moreover, effect sizes were not correlated with sample sizes $(r=0.063, P=0.214)$. Finally, the fail-safe number (i.e. number of studies that would have to be added to change the results of the meta-analysis from significant to non-significant) was 24,531 , which was much bigger than 1,955 (i.e. $5 n+10$; $n$ being the number of cases in our dataset; Rosenthal 1979; Rosenberg et al. 2000). Together, these plots and statistical tests indicate that there was no publication bias.

As an alternative to Hedges' $d$, we also calculated logresponse ratios. However, because the normal-quantile plot showed that log-response ratios were not normally distributed (ESM S3B), we present the results of analyses based on Hedges' $d$. Nevertheless, the results based on log-response ratios were qualitatively similar, and are presented in ESM S4.

Because clonal growth characteristics and invasion success are likely to be taxonomically biased, we also tested whether effect sizes varied significantly among families. Indeed, effect sizes of biomass varied significantly among families for recipient parts and donor parts, and effect sizes of asexual reproduction varied significantly among families for whole clones (ESM S5, S6). Therefore, to test whether the results are consistent within families, we repeated all analyses for the two families with $>10$ studies (Poaceae and Rosaceae).

\section{Results}

Effects of integration on performance of whole clones

Mean effect sizes for biomass of the whole clone were significantly greater than zero (Fig. 1a), indicating that 
clonal integration generally increased biomass of the whole clone. However, clonal integration did not significantly increase effect sizes for asexual reproduction of the whole clone (Fig. 1b). There were no significant differences in effect sizes between stoloniferous and rhizomatous plants (for biomass $Q_{\mathrm{b}}=0.12, P=0.750$; for asexual reproduction $Q_{\mathrm{b}}=0.12, P=0.753$; ESM S7). The results were similar within the two largest families, Poaceae and Rosaceae (ESM S8, S9); which indicates that the results were robust with respect to taxonomy.

Effects of integration on performance of potential recipient parts

Mean effect sizes for biomass and asexual reproductions of the potential recipient parts were significantly greater than zero (Fig. 1c, d), indicating that recipient parts benefited from integration. These benefits of clonal integration to recipient parts did not differ between acropetal and basipetal directions (for biomass $Q_{\mathrm{b}}=1.61, P=0.237$; for asexual reproduction $\left.Q_{\mathrm{b}}=1.43, P=0.533\right)$, between stoloniferous and rhizomatous species (for biomass $Q_{\mathrm{b}}=0.20, P=0.646$; for asexual reproduction $Q_{\mathrm{b}}=$ $1.25, P=0.290)$, between the severing approach and homogeneous-heterogeneous approach (for biomass $Q_{\mathrm{b}}=2.14, P=0.143$; for asexual reproduction $Q_{\mathrm{b}}=2.85$, $P=0.117$ ), or among different resources being translocated (i.e. carbohydrates, nutrients and water; for biomass $Q_{\mathrm{b}}=$ 5.24, $P=0.078$; for asexual reproduction $Q_{\mathrm{b}}=3.95$, $P=0.188$; ESM S7). There were some minor deviations from the overall pattern within the two largest families, Poaceae and Rosaceae, but overall the results were quite robust with respect to taxonomy (ESM S8, S9).

Effects of integration on performance of potential donor parts

Mean effect sizes for biomass and asexual reproduction of the donor parts were not significantly different from zero (Fig. 1e, f), indicating that clonal integration usually did

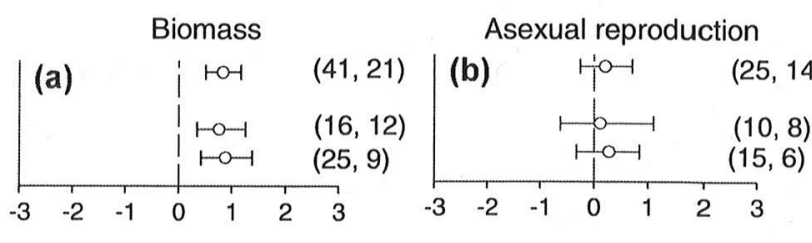

Fig. 1 Mean effect sizes (Hedges' $d$ ) of clonal integration for biomass and asexual reproduction of the whole clone (a, b), the potential recipient clone parts $(\mathbf{c}, \mathbf{d})$ and the potential donor clone part $(\mathrm{e}, \mathrm{f})$. The bars around the means denote bias-corrected $95 \%$ bootstrap confidence intervals, and a mean effect size is significantly different from zero when its $95 \%$ confidence interval does not include zero. The first and second numbers in parentheses are number of studies and number of species, respectively

Overall
Rhizomatous
Stoloniferous
Overall
Basipetal
Acropetal
Rhizomatous
Stoloniferous
Severing vs. non-severing
Heterogeneous vs. homo.
Carbohydrates
Nutrients
Water

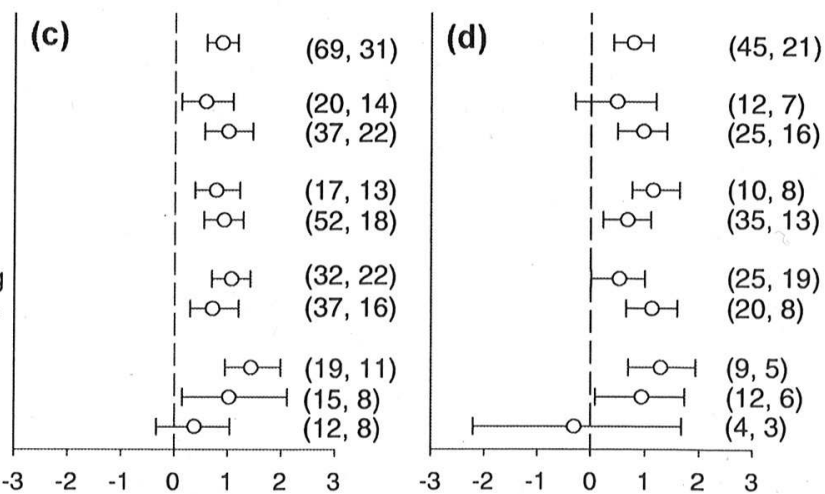

$(54,19)$

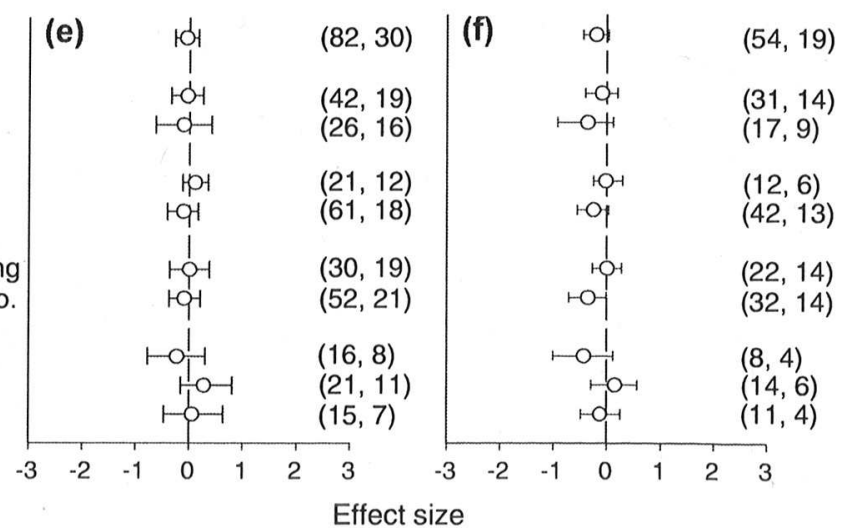


not decrease the performance of donor parts, at least not in the short term. Mean effect sizes did not differ significantly between acropetal and basipetal directions (for biomass $Q_{\mathrm{b}}=0.13, P=0.738$; for asexual reproduction $Q_{\mathrm{b}}=$ $0.99, P=0.616$ ), between stoloniferous and rhizomatous species (for biomass $Q_{\mathrm{b}}=0.77, P=0.427$; for asexual reproduction $Q_{\mathrm{b}}=0.61, P=0.428$ ), between the severing approach and homogeneous-heterogeneous approach (for biomass, $Q_{\mathrm{b}}=2.64, P=0.135$; for asexual reproduction, $Q_{\mathrm{b}}=2.06, P=0.158$ ), or among different resources (for biomass $Q_{\mathrm{b}}=0.83, P=0.723$; for asexual reproduction $Q_{\mathrm{b}}=2.80, P=0.270$; ESM S7). There were again some minor deviations from the overall pattern within the two largest families, Poaceae and Rosaceae, but overall the results were quite robust with respect to taxonomy (ESM S8, S9).

Relationships between effects of integration and global invasion success

Effect sizes of clonal integration for biomass and for asexual reproduction of whole clones were neither significantly related to the number of GCW references nor to the number of GCW regions (Table 1). The same was true for biomass and asexual reproduction of potential donor parts (Table 1). However, effect sizes of clonal integration for biomass and for asexual reproduction of potential recipient parts were significantly positively related to the number of GCW regions, and those for asexual reproduction of potential recipient parts were also significantly positively related to the number of GCW references (Table 1; Fig. 2). Within the Rosaceae, the pattern was similar to that of the overall analysis, but, for Poaceae, there was no evidence that species that give stronger support to their recipient parts are globally more invasive (ESM S10). Overall, these results indicate that species that give stronger support to their recipient parts in unfavorable patches are globally more invasive, but that this is not the case for all families.

\section{Discussion}

\section{Effects of integration on plant performance}

Our meta-analysis provided evidence that clonal integration generally increases performance-particularly biomass production - of clonal plants, at least in the short term. The benefits to the whole clones were due to significant benefits to the recipient clone parts and a lack of significant costs to the donor clone parts. This suggests that the donor parts mainly transport resources to the recipient parts, which do not affect their own immediate performance, at least not in terms of biomass production and asexual reproduction, but can still greatly increase performance of the recipient parts.

While the production of seeds allows plants to disperse to new sites and to expand populations, allocation of resources to recipient ramets is likely to be a more effective means to rapidly occupy open patches-even when they are initially stressful-once a few plants have established (Salzman and Parker 1985; Pennings and Callaway 2000; Gough et al. 2001). Moreover, while seeds usually do not provide sufficient resources to enable seedlings to outcompete established neighbors, the potentially continuous supply of resources from donor ramets may allow recipient ramets to outcompete their neighbors (Herben 2004; Yu et al. 2009; Roiloa et al. 2010). Therefore, allocation of resources to recipient ramets can importantly contribute to colonization of new sites by clonal plants.

Despite the lack of short-term costs, donor parts might have long-term costs due to a reduction in storage of carbohydrates or nutrients (Stout and Brooke 1985; Tissue and Nobel 1988). We could not address such potential longterm effects of clonal integration due to a lack of sufficient data on storage. Among the studies in our dataset, there was no effect of duration of the experiment on the effect of clonal integration (ESM S11), which might suggest that short- and long-term effects are not different. However, although the longest duration of an experiment was 770 days (Saitoh et al. 2002), the vast majority of experiments lasted $<100$ days (ESM S1). Future experimental studies should thus focus more on the long-term effects of clonal integration.

It is likely that research on clonal integration has been biased towards species that have long spacers and can easily be experimentally manipulated. This may have resulted in a morphological and taxonomic bias, which might restrict the generality of our results. Indeed, we found significant variation among families in the effects of integration (ESM S5). However, within the two largest families, Poaceae and Rosaceae, the patterns were similar to the overall pattern, indicating that these patterns are robust with regard to taxonomy. On the other hand, we cannot affirm how strong is the effect of the potential morphological bias, and in future studies species such as those with, e.g., short, thick spacers, which are less easy to manipulate experimentally, should be studied more frequently.

It has been suggested that the severing approach may overestimate the effects of integration (Jónsdóttir and Watson 1997), and that the homogeneous-heterogeneous approach may underestimate such effects (Wang et al. 2009). However, for neither recipient parts nor donor parts did we find differences in effect sizes between the different experimental approaches. This suggests that side effects of the different approaches are usually negligible. 
Table 1 Regression of effect size of clonal integration for biomass and asexual reproduction of the whole clone, the potential donor clone parts, and the potential recipient clone parts on global invasiveness of species

\begin{tabular}{|c|c|c|c|c|c|}
\hline Effect size & Measure of invasiveness & Intercept & Slope & $P$ & $n_{1}, n_{2}$ \\
\hline \multicolumn{6}{|l|}{ Whole clone } \\
\hline \multirow[t]{2}{*}{ Biomass } & $\log ($ no. of references +1$)$ & 0.715 & 0.139 & 0.645 & \multirow[t]{2}{*}{41,21} \\
\hline & $\log ($ no. of regions +1$)$ & 0.686 & 0.274 & 0.695 & \\
\hline \multirow[t]{2}{*}{ Asexual reproduction } & $\log ($ no. of references +1$)$ & 0.489 & -0.258 & 0.179 & \multirow[t]{2}{*}{25,14} \\
\hline & $\log ($ no. of regions +1$)$ & 0.346 & -0.203 & 0.337 & \\
\hline \multicolumn{6}{|l|}{ Donor part } \\
\hline \multirow[t]{2}{*}{ Biomass } & $\log ($ no. of references +1$)$ & -0.038 & -0.016 & 0.550 & \multirow[t]{2}{*}{82,30} \\
\hline & $\log ($ no. of regions +1$)$ & -0.063 & 0.014 & 0.483 & \\
\hline \multirow[t]{2}{*}{ Asexual reproduction } & $\log ($ no. of references +1$)$ & -0.240 & 0.037 & 0.338 & \multirow[t]{2}{*}{54,19} \\
\hline & $\log ($ no. of regions +1$)$ & -0.248 & 0.073 & 0.305 & \\
\hline \multicolumn{6}{|l|}{ Recipient part } \\
\hline \multirow[t]{2}{*}{ Biomass } & $\log ($ no. of references +1$)$ & -0.039 & 0.915 & 0.001 & \multirow[t]{2}{*}{69,31} \\
\hline & $\log ($ no. of regions +1$)$ & -0.211 & 1.667 & 0.002 & \\
\hline \multirow[t]{2}{*}{ Asexual reproduction } & $\log ($ no. of references +1$)$ & -0.226 & 0.930 & $<0.001$ & \multirow[t]{2}{*}{45,21} \\
\hline & $\log ($ no. of regions +1$)$ & -0.450 & 1.833 & $<0.001$ & \\
\hline
\end{tabular}

As measures of global invasiveness, we used numbers of references and regions in the global compendium of weeds. $n_{1}$ and $n_{2}$ are the numbers of studies and species in each test. Significant $(P<0.01)$ differences in bold

Fig. 2 Relationships between measures of global invasiveness: a number of global compendium of weeds references, $\mathbf{b}$ number of global compendium of weeds regions) and effect sizes ( \pm variance) of clonal integration for biomass and asexual reproduction of recipient clone parts. See Table 1 for statistical results
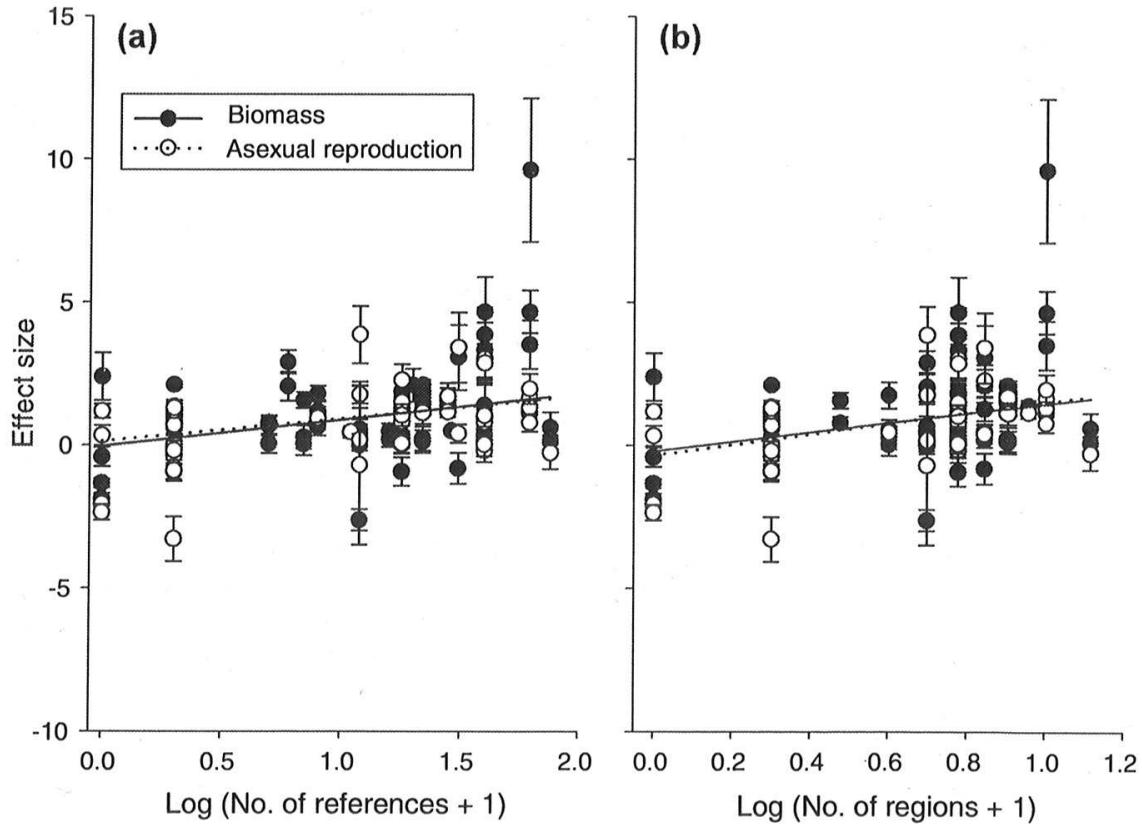

We did not find differences between stoloniferous and rhizomatous species in effects of integration for the whole clone or for the recipient and donor parts. This suggests that stoloniferous species may provide as much support to recipient parts under unfavorable conditions as do rhizomatous species. However, because rhizome connections usually persist longer than stolon connections (Jónsdóttir and Watson 1997), the long-term effects of integration could be higher for rhizomatous species.

Many studies found evidence for bidirectional translocation of resources in clonal plants, and that developmentally younger parts received more resources than developmentally older parts (de Kroon et al. 1996, 1998). The latter probably reflects the initial support of daughter 
ramets by mother ramets. Our results, however, showed that in general developmentally younger parts did not benefit more from clonal integration than older parts. A study on Carex bigelowii and Podophyllum peltatum found that nutrient and water translocation in these species could be bidirectional, while carbon could only be transported in the acropetal direction (Jónsdóttir and Watson 1997). However, we could not test whether the translocation direction of resources depends in general on the types of resources due to the small number of studies.

The translocation of mineral nutrients within clones may depend more on the existence of a water gradient (de Kroon et al. 1998) than does the gradient of carbohydrates, and resource translocation occurs in different parts of the vascular tissues (Qureshi and Spanner 1971). So, there could be different translocation capacities for the different resources. However, our results showed that the effects of clonal integration on plant performance did not differ among the three main resources (carbohydrates, nutrients and water) being translocated. This suggests that effects of clonal integration on plant performance might depend more on source-sink relationships or patch contrasts (Eriksson and Jerling 1990; Marshall et al. 1990; Caraco and Kelly 1991; Roiloa et al. 2007) than the type of resource.

Relationships between clonal integration and global invasion success

Previous studies on invasive clonal species showed that clonal integration helps these species establish and expand their populations in a new habitat (Yu et al. 2009; Aguilera et al. 2010; Xu et al. 2010). However, because these studies included only a few species that were all highly invasive, they could not conclude that clonal integration is a trait associated with invasiveness. Our meta-analysis allowed for a more objective appraisal of the available evidence. We did not find that species with larger benefits of integration for the whole clone were more invasive at a global scale. However, we found that species for which the recipient parts benefited more from integration were globally more invasive. We also found this pattern within the Rosaceae but not within the Poaceae (ESM S10). The higher benefit of integration for recipient parts could either reflect that they received more support or that they capitalized more on the support that they received. The latter would be in line with recent finding that invasive plant species frequently have higher maximum relative growth rates (Dawson et al. 2011), and that they can take more advantage of increased resource levels than non-invasive species (Dawson et al. 2012a, b). Whatever the exact mechanism, our finding contributes to the growing body of evidence (Lambdon and Hulme 2006; Pyšek and Richardson 2007; Dawson et al. 2011; van Kleunen et al. 2011) that successful invasive plants have certain traits enabling them to expand in new environments.

Open questions and directions for future research

Meta-analysis is a powerful tool to test for general patterns across studies, and to statistically summarize the current state of knowledge. However, meta-analysis also enables one to detect data deficiencies and open research questions. Below, we mention some of these open questions that should be addressed in future studies to better understand the benefits and costs of clonal integration.

1. One of the major limitations of most integration experiments conducted so far is that they lasted for less than one growing season, and we thus lack data on the long-term fitness consequences. For instance, despite the overall lack of short-term costs of integration in our meta-analysis, donor parts might have long-term costs due to a reduction in storage of carbohydrates or nutrients (Stout and Brooke 1985; Tissue and Nobel 1988), which might be related to the splitter-integrator continuum (i.e. disintegrators or splitters, restrictive integrators and full integrators; Jónsdóttir and Watson 1997). Future studies should thus look more frequently at the consequences of integration for storage, and last more than one growing season. The long-term consequences of clonal integration could also be addressed under natural conditions by assessing the effect of integration on population growth rates in demographic studies.

2. Our meta-analysis was restricted to studies that used the severing approach or the homogeneous-heterogeneous approach, because these approaches allow one to quantify performance consequences of integration. However, a limitation of both approaches is that they do not provide insights into the mechanisms of clonal integration and do not take into account that clonal plants may consist of multiple integrated physiological units (IPUs; Watson and Casper 1984; Price and Hutchings 1992). Ramets within IPUs are highly integrated, but ramets of different IPUs of the same plants are hardly integrated (Price and Hutchings 1992; Murphy and Watson 1996). Future research on clonal integration should therefore combine the severing or homogeneous-heterogeneous approaches with methods such as isotope or acid-fuchsin labeling and anatomical studies of the vascular connections between clone parts. An additional advantage of using isotopes, and quantifying the amounts translocated, would be that it allows testing whether differences in the benefit of integration reflect differences in the amount of resources being translocated or differences 
in the capacity to capitalize on the resources that are translocated (de Kroon et al. 1996, 1998).

3. In coping with heterogeneous environments, clonal plants do not only share resources among ramets though clonal integration but they can also forage for high resource patches through plasticity in spacer length and branching frequency (Slade and Hutchings 1987). However, little is known about which strategy is more advantageous or whether there is a trade-off between the ability of plastic foraging and the strength of clonal integration. Future studies should thus assess both clonal integration and foraging on the same set of species.

4. Our meta-analysis was restricted to comparisons of integration among species, but genotypes within species may also vary in their ability of clonal integration. So far, however, only a few studies have tested for such genetic variation (Alpert 1999; van Kleunen et al. 2000; Alpert et al. 2003; Chen et al. 2004; Nilsson and D'Hertefeldt 2008). Studies on heritable genetic variation in clonal integration are important as they indicate the evolutionary potential of clonal plants. Moreover, studies of whether withinspecies genetic differentiation in clonal integration is associated with certain types of habitat could provide important insights in the evolutionary forces that shape patterns in clonal integration.

5. Most studies were conducted in pots without neighbor species, and we know little about whether clonal integration can increase population growth rates of clonal plants in the field, especially in the long run. Moreover, the existence of competition with neighbors might affect the benefit and cost of clonal integration (e.g., Hartnett 1993; Wang et al. 2009), but we know little about whether clonal integration confers competitive ability to clonal plants, and whether such effects are relevant to the habitats where the plants grow.

\section{Conclusions}

Clonal integration has positive effects on plant performance, both for stoloniferous and rhizomatous species, at least in the short term. These benefits to the clone are due to benefits for the recipient clone parts and the absence of major costs to the donor clone parts, irrespective of the relative developmental age of these clone parts. Species with larger benefits of clonal integration are not more invasive at a global scale, but species in which recipient clone parts growing in unfavorable patches benefit more from integration are more invasive. Although there still are many open questions for future research, the results of our meta-analysis demonstrate general performance benefits of clonal integration and strongly suggest that clonal integration contributes to the success of clonal plants.

Acknowledgments We thank Anna Aguilera, Liu Jian and Xiao $\mathrm{Ke}-$ Yan for providing data, and Dr. Laura Gough and two anonymous referees for helpful comments on an earlier version of the manuscript. This research was supported by the External Cooperation Program of the Chinese Academy of Sciences (Grant GJHZ0904 to FHY) and the National Nature Science Foundation of China (Grant 31070371 to FHY), and the Sino-Swiss Science and Technology Cooperation (Grant JRP IZLC3 123973 to M.v.K. and M.F.). The authors declare that they have no conflict of interest and the study complies with the current laws of China.

\section{References}

Adams DC, Gurevitch J, Rosenberg MS (1997) Resampling tests for meta-analysis of ecological data. Ecology 78:1277-1283

Aguilera A, Alpert P, Dukes J, Harrington R (2010) Impacts of the invasive plant Fallopia japonica (Houtt.) on plant communities and ecosystem processes. Biol Invasions 12:1243-1252

Alpert P (1999) Clonal integration in Fragaria chiloensis differs between populations: ramets from grassland are selfish. Oecologia 120:69-76

Alpert P, Holzapfel C, Slominski C (2003) Differences in performance between genotypes of Fragaria chiloensis with different degrees of resource sharing. J Ecol 91:27-35

Brooker RW, Callaghan TV, Jonasson S (1999) Nitrogen uptake by rhizomes of the clonal sedge Carex bigelowii: a previously overlooked nutritional benefit of rhizomatous growth. New Phytol 142:35-48

Caraco T, Kelly CK (1991) On the adaptive value of physiological integration in clonal plants. Ecology 72:81-93

Chen JS, Yu D, Liu Q, Dong M (2004) Clonal integration of the stoloniferous herb Fragaria vesca from different altitudes in Southwest China. Flora 199:342-350

Dawson W, Fischer M, van Kleunen M (2011) The maximum relative growth rate of common UK plant species is positively associated with their global invasiveness. Glob Ecol Biogeogr 20:299-306

Dawson W, Rohr RP, van Kleunen M, Fischer M (2012a) Alien plant species with a wider global distribution are better able to capitalize on increased resource availability. New Phytol 194: 859-867

Dawson W, Fischer M, van Kleunen M (2012b) Common and rare plant species respond differently to fertilisation and competition, whether they are alien or native. Ecol Lett. doi:10.1111/j. 1461-0248.2012.01811.x

de Kroon H, Hutchings MJ (1995) Morphological plasticity in clonal plants: the foraging concept reconsidered. J Ecol 83:143-152

de Kroon H, Fransen B, Rheenen JWA, Dijk A, Kreulen R (1996) High levels of inter-ramet water translocation in two rhizomatous Carex species, as quantified by deuterium labelling. Oecologia 106:73-84

de Kroon H, Kreulen R, van Rheenen JWA, van Dijk A (1998) The interaction between water and nitrogen translocation in a rhizomatous sedge (Carex flacca). Oecologia 116:38-49

D'Hertefeldt T, Jónsdóttir IS (1999) Extensive physiological integration in intact clonal systems of Carex arenaria. J Ecol $87: 258-264$ 
Dong M, de Kroon H (1994) Plasticity in morphology and biomass allocation in Cynodon dactylon, a grass species forming stolons and rhizomes. Oikos 70:99-106

Dong M, During HJ, Werger MJA (1996) Morphological responses to nutrient availability in four clonal herbs. Plant Ecol 123:183-192

Eriksson O, Jerling L (1990) Hierarchical selection and risk spreading in clonal plants. In: van Groenendae J, de Kroon H (eds) Clonal growth in plants: regulation and function. SPB, The Hague, pp 79-94

Gough L, Goldberg DE, Hershock C, Pauliukonis N, Petru M (2001) Investigating the community consequences of competition among clonal plants. Evol Ecol 15:547-563

Gurevitch J, Hedges L (2001) Meta-analysis: combining the results of independent experiments. In: Scheiner SM, Gurevitch J (eds) Design and analysis of ecological experiments. Oxford University Press, Oxford, pp 347-369

Hartnett DC (1993) Regulation of clonal growth and dynamics of Panicum virgatum (Poaceae) in tallgrass prairie: effects of neighbor removal and nutrient addition. Am J Bot 80:1114-1120

He WM, Alpert P, Yu FH, Zhang LL, Dong M (2011) Reciprocal and coincident patchiness of multiple resources differentially affects benefits of clonal integration in two perennial plants. J Ecol 99:1202-1210

Herben T (2004) Physiological integration affects growth form and competitive ability in clonal plants. Evol Ecol 18:493-520

Herben T, Suzuki JI (2002) A simulation study of the effects of architectural constraints and resource translocation on population structure and competition in clonal plants. Evol Ecol 15:403-423

Hutchings MJ, Wijesinghe DK (1997) Patchy habitats, division of labour and growth dividends in clonal plants. Trends Ecol Evol 12:390-394

Jenkins C, Keller S (2011) A phylogenetic comparative study of preadaptation for invasiveness in the genus Silene (Caryophyllaceae). Biol Invasions 13:1471-1486

Jennions MD, Møller AP (2002) Publication bias in ecology and evolution: an empirical assessment using the 'trim and fill' method. Biol Rev 77:211-222

Jónsdóttir I, Watson M (1997) Extensive physiological integration: an adaptive trait in resource-poor environments? In: de Kroon $\mathrm{H}$, van Groenendael $\mathbf{J}$ (eds) The ecology and evolution of clonal plants. Backhuys, Leiden, pp 109-136

Klimeš L, Klimešova J, Hendriks R, van Groenendael J (1997) Clonal plant architecture: a comparative analysis of form and function. In: de Kroon H, van Groenendael J (eds) The ecology and evolution of clonal plants. Backhuys, Leiden, pp 1-29

Lambdon PW, Hulme PE (2006) Predicting the invasion success of Mediterranean alien plants from their introduction characteristics. Ecography 29:853-865

Leimu R, Mutikainen PIA, Koricheva J, Fischer M (2006) How general are positive relationships between plant population size, fitness and genetic variation? J Ecol 94:942-952

Liu J, Dong M, Miao S, Li Z, Song M, Wang R (2006) Invasive alien plants in China: role of clonality and geographical origin. Biol Invasions 8:1461-1470

Lowe S, Browne M, Boudjelas S, De Poorter M (2000) 100 of the world's worst invasive alien species a selection from the global invasive species database. The Invasive Species Specialist Group (ISSG) a specialist group of the Species Survival Commission (SSC) of the World Conservation Union (IUCN): 12. Electronic version available at website http://www.issg.org/booklet.pdf

Marshall C, van Groenendael J, de Kroon H (1990) Source-sink relations of interconnected ramets. In: van Groenendael J, de Kroon $\mathrm{H}$ (eds) Clonal growth in plants: regulation and function. SPB, The Hague, pp 23-41

Murphy N, Watson MA (1996) Sectorial root growth in cuttings of Coleus rehneltianus in response to localized aerial defoliation. Plant Ecol 127:17-23
Nilsson J, D'Hertefeldt T (2008) Origin matters for level of resource sharing in the clonal herb Aegopodium podagraria. Evol Ecol 22:437-448

Palmer AR (1999) Detecting publication bias in meta-analyses: a case study of fluctuating asymmetry and sexual selection. Am Nat 154:220-233

Pan JJ, Price JS (2001) Fitness and evolution in clonal plants: the impact of clonal growth. Evol Ecol 15:583-600

Pennings SC, Callaway RM (2000) The advantages of clonal integration under different ecological conditions: a communitywide test. Ecology 81:709-716

Poor A, Hershock C, Rosella K, Goldberg DE (2005) Do physiological integration and soil heterogeneity influence the clona growth and foraging of Schoenoplectus pungens? Plant Ecol 181:45-56

Prach K, Pyšek P (1994) Clonal plants-what is their role in succession? Folia Geobot 29:307-320

Price EAC, Hutchings MJ (1992) The cause and developmental effects of integration and independence between different parts of Glechoma hederacea clones. Oikos 63:376-386

Pyšek P (1997) Clonality and plant invasions: can a trait make a difference? In: de Kroon $\mathrm{H}$, van Groenendael J (eds) The ecology and evolution of clonal plants. Backhuys, Leiden, pp 405427

Pyšek P, Richardson D (2007) Traits associated with invasiveness in alien plants: where do we stand? In: Nentwig W (ed) Biological invasions. Ecological Studies. Springer, Berlin, pp 97-126

Pyšek P, Jarošík V, Pergl J, Randall R, Chytrý M, Kühn I, Tichý L, Danihelka J, Chrtek jun J, Sádlo J (2009) The global invasion success of Central European plants is related to distribution characteristics in their native range and species traits. Divers Distr 15:891-903

Qureshi FA, Spanner DC (1971) Unidirectional movement of tracers along the stolon of Saxifraga sarmentosa. Planta 101:133-146

Randall RP (2002) A global compendium of weeds. Richardson, Melbourne

Richardson DM, Rejmánek M (2004) Conifers as invasive aliens: a global survey and predictive framework. Divers Distr 10:321-331

Roiloa SR, Alpert P, Tharayil N, Hancock G, Bhowmik PC (2007) Greater capacity for division of labour in clones of Fragaria chiloensis from patchier habitats. J Ecol 95:397-405

Roiloa S, Rodríguez-Echeverría S, de la Peña E, Freitas H (2010) Physiological integration increases the survival and growth of the clonal invader Carpobrotus edulis. Biol Invasions 12:1815-1823

Rosenberg MS, Adams DC, Gurevitch J (2000) Metawin: statistical software for meta-analysis. Sinauer, Sunderland

Rosenthal R (1979) The "file drawer problem" and tolerance for null results. Psychol Bull 86:638-641

Saitoh T, Seiwa K, Nishiwaki A (2002) Importance of physiological integration of dwarf bamboo to persistence in forest understorey: a field experiment. J Ecol 90:78-85

Salzman AG, Parker MA (1985) Neighbors ameliorate local salinity stress for a rhizomatous plant in a heterogeneous environment. Oecologia 65:273-277

Schlaepfer DR, Glättli M, Fischer M, van Kleunen M (2010) A multispecies experiment in their native range indicates pre-adaptation of invasive alien plant species. New Phytol 185:1087-1099

Slade AJ, Hutchings MJ (1987) An analysis of the costs and benefits of physiological integration between ramets in the clonal perennial herb Glechoma hederacea. Oecologia 73:425-431

Stout D, Brooke B (1985) Rhizomes and roots below clipped pinegrass tillers have a higher percent carbohydrate when attached to other nonclipped tillers. J Range Manag 38:276-277

Stuefer JF, During HJ, de Kroon H (1994) High benefits of clonal integration in two stoloniferous species, in response to heterogeneous light environments. J Ecol 82:511-518 
Suzuki JI, Stuefer JF (1999) On the ecological and evolutionary significance of storage in clonal plants. Plant Spec Biol 14:11-17

Tamm A, Kull K, Sammul M (2002) Classifying clonal growth forms based on vegetative mobility and ramet longevity: a whole community analysis. Evol Ecol 15:383-401

Tissue DT, Nobel PS (1988) Parent-ramet connections in Agave deserti: influences of carbohydrates on growth. Oecologia 75:266-271

van Kleunen M, Stuefer JF (1999) Quantifying the effects of reciprocal assimilate and water translocation in a clonal plant by the use of steam-girdling. Oikos 85:135-145

van Kleunen M, Fischer M, Schmid B (2000) Clonal integration in Ranunculus reptans: by-product or adaptation? J Evol Biol 13:237-249

van Kleunen M, Fischer M, Schmid B (2002) Experimental life-history evolution: selection on the allocation to sexual reproduction and its plasticity in a clonal plant. Evolution 56:2168-2177

van Kleunen M, Schlaepfer DR, Glaettli M, Fischer M (2011) Preadapted for invasiveness: do species traits or their plastic response to shading differ between invasive and non-invasive plant species in their native range? J Biogeogr 38:1 294-1304

Wang N, Yu FH, Li PX, He WM, Liu J, Yu GL, Song YB, Dong M (2009) Clonal integration supports the expansion from terrestrial to aquatic environments in the amphibious stoloniferous herb Alternanthera philoxeroides. Plant Biol 11:483-489

Watson MA, Casper BB (1984) Morphogenetic constraints on patterns of carbon distribution in plants. Annu Rev Ecol Syst $15: 233-258$

Xu CY, Schooler SS, Klinken RDV (2010) Effects of clonal integration and light availability on the growth and physiology of two invasive herbs. J Ecol 98:833-844

Yu FH, Wang. N, He WM, Chu Y, Dong M (2008) Adaptation of rhizome connections in drylands: increasing tolerance of clones to wind erosion. Ann Bot 102:571-577

Yu FH, Wang N, Alpert P, He WM, Dong M (2009) Physiological integration in an introduced, invasive plant increases its spread into experimental communities and modifies their structure. Am J Bot 96:1983-1989 